\title{
Concept study of a new method for drying dishware in a heat pump dishwasher
}

\author{
Peder Bengtsson (D) Jonas Berghel
}

Received: 12 December 2016 / Accepted: 25 June 2017 / Published online: 10 July 2017

(C) The Author(s) 2017. This article is an open access publication

\begin{abstract}
In a heat pump dishwasher, the whole dishwasher with the cabinet, dishware and process water is the heat sink, while a water tank, whose contents will freeze, is the heat source. The aim of the experimental concept study presented here was to evaluate a new drying method for a heat pump dishwasher. In this method, the drying of the dishware occurs as a fan circulates humid air in a closed system in which the water on the dishware evaporates inside the warm dishwasher cabinet and then condenses on a cold surface of the frozen water tank. The evaluation of drying performance was based on the European standard EN50242, which considers visible water drops left on the dishware after a completed dishwashing cycle. The results showed that this new closed drying method was more energy efficient compared to an existing open drying method and that the drying start temperature and the drying time had a significant effect on the drying performance. Its lower electricity consumption and the fact that it does not vent humid air into the kitchen give this heat pump dishwasher a competitive advantage over dishwashers using an open drying method.
\end{abstract}

P. Bengtsson

ASKO Appliances AB, Sockerbruksgatan 3, 53140 Lidköping, Sweden

P. Bengtsson $(\bowtie) \cdot J$. Berghel

Environmental and Energy Systems, Karlstad University, 651

88 Karlstad, Sweden

e-mail: Peder.Bengtsson@asko.se
Keywords Energy reduction · Home appliances . Condensation drying $\cdot$ Freezing

\section{Introduction}

In the household appliance industry, as in many other industries, it is crucial to have products with low electricity consumption. Buyers are aware of the positive impact of low electricity consumption on both their personal economy and on the environment (Jeong and Kim 2015). Manufacturers in Europe are obliged to put a label showing the electricity consumption on the front of a household product. In the case of dishwashers, this consumption must be determined in accordance with the European standard EN50242 (EN50242 2008).

Although low electricity consumption is important to the customer when choosing which dishwasher to buy, parameters such as its cleaning and drying performance are also important. These two parameters are also included and defined in the European dishwashing standard EN50242 (EN50242 2008), but only the drying performance is displayed on the front of the product. There are legal requirements for minimum drying (A) and cleaning for all dishwashers sold in the European market. A core business concern for dishwasher manufacturers is to reach this minimum cleaning and the drying performance while using the lowest possible amount of electricity.

The washing process in a household dishwasher is divided into four operational steps: prewashing, washing, rinsing and drying (Fig. 1). Simulations showed that 


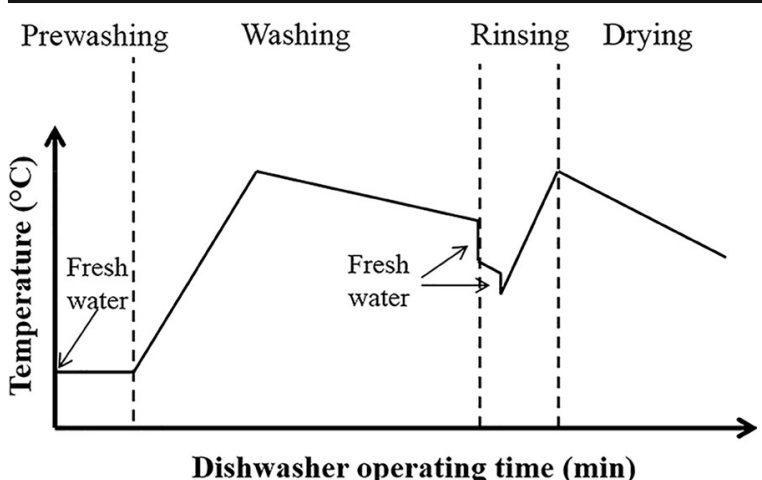

Fig. 1 Dishwashing cycle and the four operation steps: prewashing, washing, rinsing and drying

between 80 and $90 \%$ of all electricity consumption occurs during the heating in the washing and rinsing steps (Bengtsson et al. 2015). The rest can be attributed to the water circulation pump.

The heating in the washing step is needed for the washing process with the detergent. The heating in the rinsing step is needed to heat the machine and the dishware to a high temperature before the drying step.

Drying of dishware in a dishwasher

Drying is an energy-intensive process, most of which takes place with low thermal efficiency (Sai and Linga 2010). It involves heat, mass and momentum transfers. When a porous body is drying, two processes are involved (Mujumdar 1995): transportation of water inside the material and evaporation of the water on the surface. However, when drying dishware, which is not porous, only one process occurs, namely evaporation of the remained water on the surfaces. The amount of this remaining water was reduced by adding rinse aid during the rinsing step.

Drying dishware in a dishwasher does not involve the transmission of heat from the environment to the dishware during the drying. Instead, the heat accumulated in the final rinse step is used to evaporate water from the dish surfaces. Therefore, the final rinse temperature, which is the same as the drying start temperature, is an important factor when drying dishware (Lee and Jeong 2014). At the beginning of the drying process, $100 \%$ of the dishware area is wet, but at the end, only a small part of the area should be wet. For example, for a normal dinner plate, only one or two drops should remain on the surface by the end of the drying stage for it to be considered dry. This is in accordance with the European standard EN50242 (EN50242 2008). A rough calculation shows that these two drops cover only $0.13 \%$ of the total surface area of a normal dinner plate.

Current dishwashers use various main methods to dry dishware. However, in practice, there will always be a small part of drying which uses method $b$ in the other drying methods. These methods may be open or closed, dynamic (with a fan) or static (without a fan). If there is no fan, the air velocity around the dishware is due to natural convection (Fig. 2).

In a static open drying method (Samsung dishwasher DW60H9970SA n.d.), the door of the dishwasher opens slightly to let humid air escape into the kitchen by convection (method a in Fig. 2).

A static closed drying method (Bosch dishwasher SHX55M06UC n.d.) involves water condensing on the cabinet surfaces (method $b$ in Fig. 2). The drying occurs because the temperature of the dishware is always higher than that of the cabinet surfaces, which are cooled by the surroundings in the kitchen. During drying, the humid air transported water from the dishware to the cabinet surfaces and then drained to the bottom of the dishwasher.

In a dynamic open drying method (ASKO n.d.), a fan transports the humid air from the cabinet to the kitchen (method $\mathrm{c}$ in Fig. 2). In the present study, this is the reference drying method and is referred to as the existing method.

A dynamic closed drying method was evaluated with a parameter study in an experimental setup (Lee and Jeong 2014) (method d in Fig. 2) which investigated the influence of drying start temperature, airflow and drying time. It was concluded that a higher drying start temperature affects the drying most and results in better drying performance. The definition of drying performance in their method was by visual inspection for water on the dishware surfaces according to a slightly modified version of the European dishwashing standard EN50242 (EN50242 2008).

Another dynamic closed airflow process uses a container of zeolite to adsorb water from the humid air coming from the dishwasher cabinet (Hauer and Fischer 2011; Santori et al. 2013) (method e in Fig. 2). An experimental parameter study of the type of zeolite, geometry of the container of zeolite and airflow led to the conclusion that a high airflow results in better drying performance (Santori et al. 2013). Here, drying performance was defined as the amount of water adsorbed by the zeolite. 


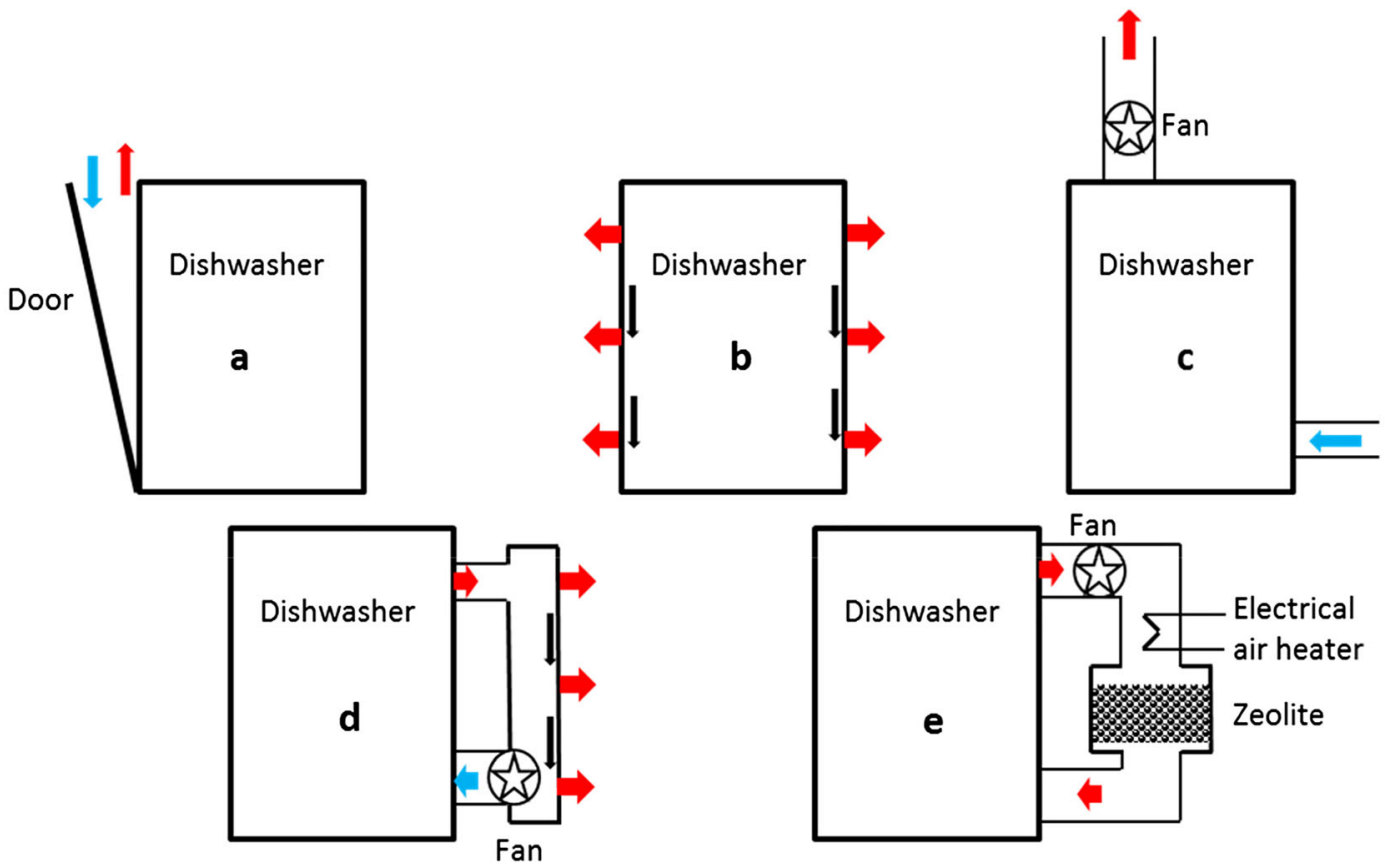

Fig. 2 Five current methods for drying dishware in a dishwasher: a static open, b static closed, $\mathbf{c}$ dynamic open, $\mathbf{d}$ dynamic closed and $\mathbf{e}$ dynamic closed adsorption drying with zeolite. The thin black arrows represent condensed water in $\mathbf{b}$ and $\mathbf{d}$

In both of the open methods (a and c in Fig. 2), humid air exhausts from the dishwasher into the kitchen. This humid air affects the climate in the kitchen and can damage the kitchen interior.

A new approach to decreasing the electricity consumption is to add a heat pump system and a water tank to the dishwasher (Bengtsson and Berghel 2016; Bengtsson et al. 2015; Bengtsson and Eikevik 2016). The heat pump system includes a compressor, capillary tube, a condenser inside the dishwasher cabinet and an evaporator in a water tank. The dishwasher cabinet, including the dishware and dishwater, acts as the heat sink, and the water in the tank, which freezes, is the heat source. Bengtsson et al. showed that this concept has the potential to decrease the total electricity consumption by $24 \%$ compared to heating the dishwasher with an electrical element (Bengtsson et al. 2015). At the start of the drying step in this heat pump dishwasher, the cabinet and the dishware are warm, while the water in the tank is cold with a large proportion of ice. Adding a heat pump system has only been implemented in one dishwasher on the market. It was the V-ZUG Adora SL WP (http://www.vzug.com/gb/en/int_novelties_heatpump_ dishwasher_2014_vzug (accessed 170228)), which appeared on the market in 2014 with the energy label $(\mathrm{A}+++-40 \%)$ in the EU energy labelling system, and it had an electricity consumption of $0.48 \mathrm{kWh} /$ cycle. VZUG uses drying method a in Fig. 2.

The new in this study was to introduce a drying method which is a dynamic closed method that dries the dishware by circulating the humid air from the cabinet against the cold surface of the water tank in a heat pump dishwasher (Fig. 3). Condensation, which decreases the absolute humidity of the air, occurs if the wall temperature of the tank falls below the dew point. Most of the cooling energy (represented by the melting enthalpy and cooling of water in the water tank) during the drying process comes from the ice in the water tank, which is created during the heating with the heat pump system. The fact that the water tank is full of ice when the drying step starts means that it holds onto the surface where the water in the humid air condenses to cold during the whole drying step. One major benefit of this closed drying is that there is no venting of humid air to the kitchen.

The dryness of a porous product is normally defined by weighing the product before and after the drying process. Dishware, however, is nonporous; thus, the definition of dryness is based on whether visible water is left on the surface of the dishware after the drying step, in line with the European dishwashing standard EN50242 (EN50242 2008). 
Fig. 3 Representation of drying dishware in a heat pump dishwasher. Warm humid air circulates against the cold surface of a frozen water tank. The thin black arrows on the water tank represent condensed water. Air properties were measured at the two places marked in the ducts. The three measurement points on the water tank were located on the surface, outside the water tank

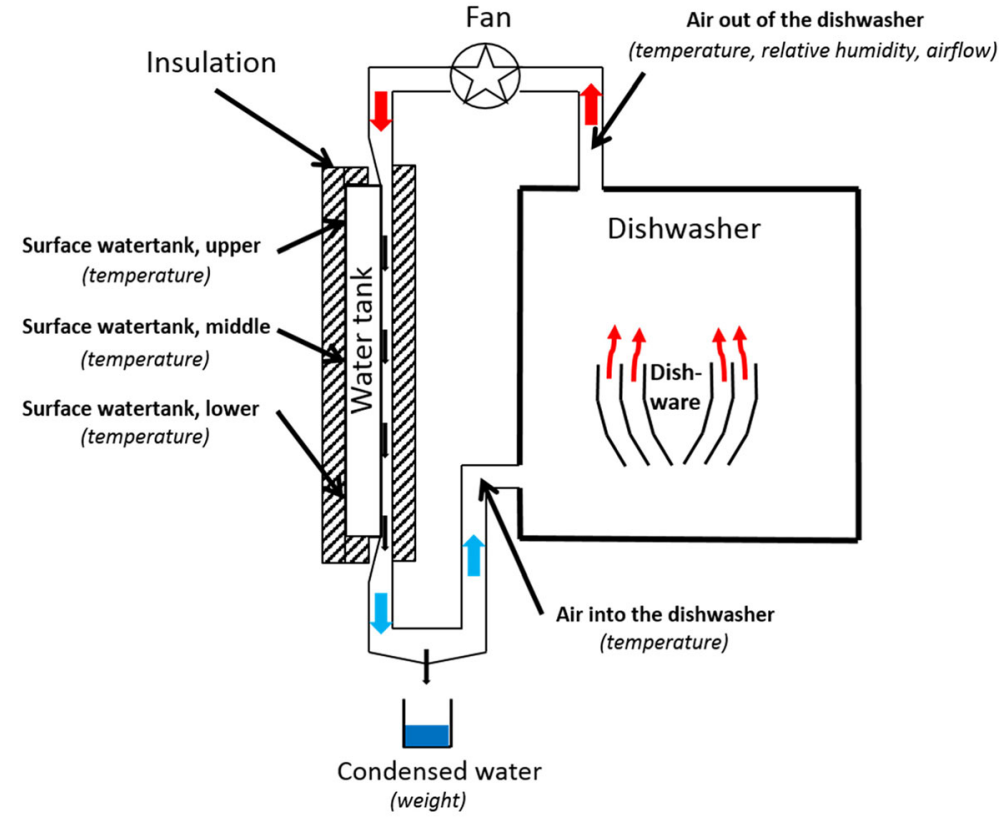

The aim of this concept study was to investigate the drying performance of a new method of drying dishware in a heat pump dishwasher in comparison with an existing drying method available in the market. The effects of the amount of ice in the water tank, the drying start temperature, airflow and drying time were evaluated with an experimental setup. The evaluation of the drying performance was based on visual inspection of the dishware. Evaluation of the drying performance of the dishware by the amount of condensate from the water tank surface was also compared to the method using visual inspection.

\section{Methods}

An experimental setup based on an existing dishwasher was designed and constructed. This setup was built to handle experiments with both the new drying method (see Fig. 3) and the existing method (method c in Fig. 2).

\section{Experimental setup}

The experimental setup was based on an existing dishwasher (ASKO 90.2HWC). A heat pump system, water tank, fan and air duct system were added (Fig. 3).

Figure 3 shows the location of the drying components. The water tank consists of a container filled with 5.91 of water and insulated all around with $50 \mathrm{~mm}$ of mineral wool. The air duct that runs along one of the water tank surfaces has a width of $500 \mathrm{~mm}$, a length of $450 \mathrm{~mm}$ and a height of $5 \mathrm{~mm}$. The speed of the fan was adjustable to allow variable airflows. The mass of the unloaded machine was $50 \mathrm{~kg}$. When loaded, it contained 31 of water and $33 \mathrm{~kg}$ of dishware. The overall heat capacity of the machine, dishware and water was calculated from measurements to be about $0.02 \mathrm{kWh} /{ }^{\circ} \mathrm{C}$.

The heat pump system was described in detail in earlier studies (Bengtsson and Berghel 2016; Bengtsson et al. 2015; Bengtsson and Eikevik 2016). A reference drying experiment using method c in Fig. 2 was performed with the same experimental setup.

K-type thermocouple probes $\left( \pm 0.23^{\circ} \mathrm{C}\right)$ were used to measure the temperature, and the signals were logged using a Pico Logger TC-08 Thermocouple Data Logger $\left( \pm 0.23{ }^{\circ} \mathrm{C}\right)$. The temperatures and the humidity were placed $25 \mathrm{~mm}$ into the inlet, and the outlet tubes were measured from the dishwasher. The mass of the condensed water was measured using an AND EK-12KA scale $( \pm 0.1 \mathrm{~g})$. The airflow was measured with a Prandtl tube, which was placed in the outlet tube with the correct distance of straight tubes before and after.

The dishwasher (ASKO 90.2HWC) in this experimental setup was designed to be loaded with 13 settings of dishware. The type of dishware is defined by the European dishwashing standard EN50242 (EN50242 2008). The dishware was placed in the dishwasher according to the manufacturer's specifications which can be obtained from 
the manufacturer (ASKO 2017). The total number of dishware are 13 soup plates, 13 dinner plates, 13 dessert dishes, 13 saucers, 13 glass, 13 cups, 1 oval platter, 1 large serving bowl, 1 medium serving bowl, 1 dessert bowl, 13 teaspoons, 13 dessert spoons, 13 forks, 13 knives, 1 serving fork, 1 gravy ladle and 2 serving spoons.

Drying performance (visual inspection)

A slightly modified version of the European dishwashing standard EN50242 (EN50242 2008) was used in this study, as set out below (Lee and Jeong 2014).

The visual inspection of the dishware is done piece by piece in an optional order. In this study, the lower basket was inspected first, followed by the upper basket and the cutlery basket. The total time for the inspection of one item should be $8 \mathrm{~s}$, of which the visual inspection should take $3 \mathrm{~s}$.

Each piece was assigned 2, 1 or 0 points according to Table 1. When all pieces had been inspected, the points were summed. For 13 settings, which included 151 pieces, the maximum total points are 302 .

In the final step, according to EN50242 (EN50242 2008), the sum of the points should be compared to the sum of the points from a calibrated reference dishwasher operating at the same time. The result from this reference dishwasher is the target for achieving legal requirements for minimum drying performance.

In the slightly modified method (Lee and Jeong 2014) of EN50242 (EN50242 2008) used in this study, this final step was not included. Instead, an average score of between 0 and 2 (for all 151 pieces) was used (Lee and Jeong 2014) (Eq. (1)).

$$
\text { Drying performance }=\frac{\text { Sum of points }}{151}
$$

Table 1 Criteria for estimating drying performance of dishware according to the European dishwashing standard EN50242 (Jeong and Kim 2015)

\begin{tabular}{ll}
\hline Visual inspection of one piece & Points \\
\hline No water & 2 \\
One or two drops with a total wet area less than $50 \mathrm{~mm}^{2}$ & 1 \\
More than two drops or a total wet area over $50 \mathrm{~mm}^{2}$ & 0 \\
\hline
\end{tabular}

\section{Reference test}

The reference experiment with the existing drying method (method c in Fig. 2) was performed on the experimental setup and used as a reference drying performance. The manufacturer's settings were used with the drying start temperature set to $48^{\circ} \mathrm{C}$, airflow $8 \mathrm{~m}^{3} / \mathrm{h}$ and a drying time of $75 \mathrm{~min}$ to reach the drying rating (A) according to EN50242 (EN50242 2008).

\section{Experiment test series 1}

Test series 1 consisted of 16 experiments to examine the influence of three parameters: the amount of ice in the water tank, the drying start temperature and the airflow (Table 2). The drying start temperature affects the performance because it defines the total available accumulated heat that can be used to evaporate water from the dish surfaces (Lee and Jeong 2014). Similarly, the total amount of ice in the water tank represents the amount of available cooling energy to condense water against the water tank surface. The airflow is evaluated because the air transports the water from the dishware to the water tank surface (Lee and Jeong 2014; Hauer and Fischer 2011; Santori et al. 2013). The range of the parameters was based on the reference test with the existing method, namely $48^{\circ} \mathrm{C}, 8 \mathrm{~m}^{3} / \mathrm{h}$ and $75 \mathrm{~min}$.

\section{Experiment test series 2}

Test series 2 was based on the results from test series 1 . It included 24 experiments and examined the influence of the amount of ice in the water tank and the drying time (Table 3). The drying performance value obtained for the existing method in the reference test was 1.58 . This value was assumed to be the limit for an approved drying performance in test series 2 . The drying start temperature for each experiment was selected to be as

Table 2 Parameter test series 1 evaluating the impact of the amount of ice in the water tank, drying start temperature and airflow

\begin{tabular}{ll}
\hline & Tested parameters \\
\hline Amount of ice in the water tank & $0,0.19,1.03$ and $1.87 \mathrm{~kg}$ \\
Drying start temperature & 44 and $48^{\circ} \mathrm{C}$ \\
Airflow & 8 and $12 \mathrm{~m}^{3} / \mathrm{h}$ \\
Drying time & $75 \mathrm{~min}$ \\
\hline
\end{tabular}


Table 3 Parameter test series 2 evaluating the impact of the amount of ice in the water tank and drying time

Tested parameters

\begin{tabular}{ll}
\hline Amount of ice in the & $0,0.05,0.19,0.61,1.03,1.45,1.87$ and \\
water tank & $2.29 \mathrm{~kg}$ \\
Drying performance & 1.58 \\
Airflow & $8 \mathrm{~m}^{3} / \mathrm{h}$ \\
Drying time & 60,75 and $90 \mathrm{~min}$ \\
\hline
\end{tabular}

low as possible to reach a drying performance just above 1.58 , which represents the drying rating (A) according to EN50242 (EN50242 2008).

Method for performing the experiments

All the experiments were performed according to the following protocol:

1. Fill the dishwasher with 41 of water.

2. Start the circulation of water and the compressor and continue for a predetermined time to achieve the required amount of ice in the water tank.

3. Add $5 \mathrm{ml}$ of rinse aid.

4. Start the circulation of water and the resistive heating and continue until the predetermined drying start temperature was reached.

5. Turn off the circulation of water and the resistive heater.

6. Wait 1 min until the water is pumped out of the dishwasher.

7. Start the drying fan and continue until the predetermined drying time is reached.

8. Wait $30 \mathrm{~min}$.

9. Start the visual inspection in accordance with the previously described procedure for determining drying performance.

\section{Results and discussion}

All drying performances were based on visual inspection of the dishware. This is not an exact method, a point that must be considered when evaluating the results. However, the fact that all experiments were performed according to the European dishwashing standard EN50242 (EN50242 2008) by the same person, with the same type of visual assessment, improves the reliability of the results.
Figure 4 shows the drying performance from test series 1 . The drying performance of 1.58 from the reference test with the existing method is also shown for comparison. In three experiments with the same drying start temperature $\left(48{ }^{\circ} \mathrm{C}\right)$ and a large amount of ice, the drying performance was better with the new drying method. This showed that the new drying method has the potential to be more energy effective than the existing method.

As in other studies (Lee and Jeong 2014; Santori et al. 2013), the drying start temperature has a large effect on the drying performance. When comparing drying start temperatures of 44 and $48^{\circ} \mathrm{C}$, the drying performance was higher at $48{ }^{\circ} \mathrm{C}$. This result was expected because no heat is transmitted from the environmental air to the dishware during drying (Lee and Jeong 2014). The amount of heat available during the drying period is represented by the drying start temperature.

Changes in the airflow showed no clear impact on the drying performance in Fig. 4. However, the airflow affects the temperatures and the relative humidity of the air throughout transient drying. The appearance of the curves in Fig. 5 is shown as an example to clarified.

At the beginning of the drying step, the air which came out of the dishwasher was saturated and it had adsorbed as much water as possible from the dishware at the current temperature. By the end of the drying step, the relative humidity was lower than $60 \%$ and water could be adsorbed from the dishware. These different conditions require different airflows in order to optimally dry the dishware throughout the whole drying step. The fact that the drying performances are similar for the two airflows in Fig. 4 could be due to a compromise between more effective and less effective drying periods.

In the study with the drying method using zeolite (Santori et al. 2013) (method e in Fig. 2), it was claimed that drying performance varied with airflow. This may occur because heat is released from the zeolite when it adsorbs water during the drying cycle. In this study, all the available heat is represented by the drying start temperature; no additional heat was added during the drying. This difference between the drying methods may explain the different results relating to airflow.

Figure 6 shows that a longer drying time allows a lower drying start temperature to reach the drying performance of 1.58 , with ice loads between 0 and $1.03 \mathrm{~kg}$. The lowest drying start temperature $\left(46{ }^{\circ} \mathrm{C}\right)$ is feasible for ice loads above $1.03 \mathrm{~kg}$ for 60 and 90-min drying time. The same temperature is feasible with more than 
Fig. 4 Drying performance in test series 1 with different airflows, amounts of ice and drying start temperatures, with an uncertainty of \pm 0.01 . For comparison, the drying performance of the existing drying method in the reference test is shown in the first position. In all experiments, the drying time was $75 \mathrm{~min}$

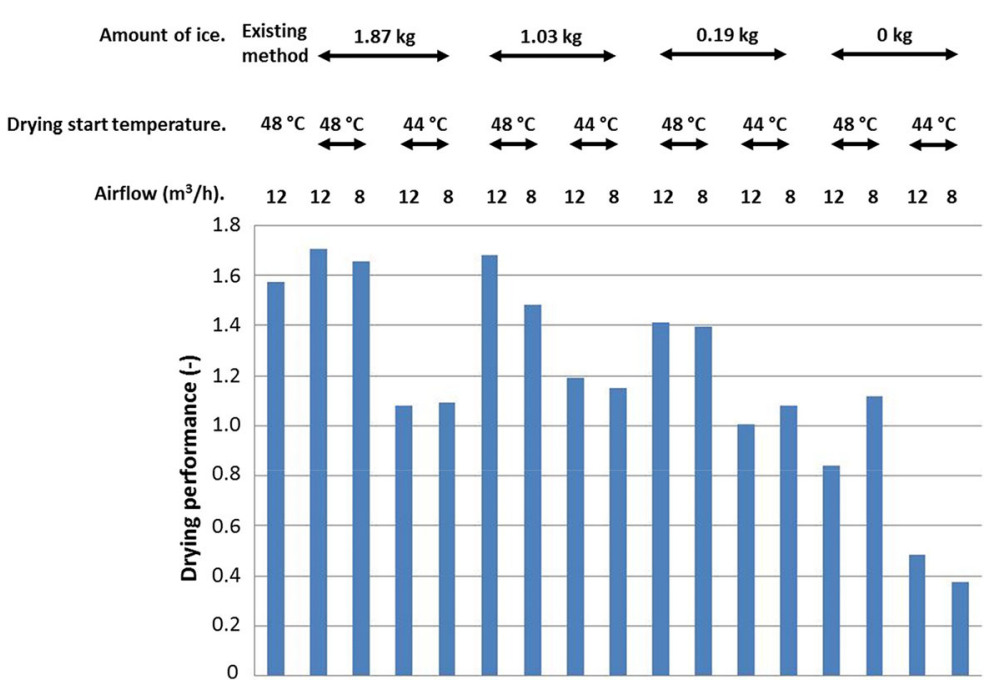

Compared with the existing method $\left(48{ }^{\circ} \mathrm{C}\right.$ and $75 \mathrm{~min}$ ), the new drying method allows a lower drying start temperature of $46^{\circ} \mathrm{C}$ with the same drying time if the amount of ice is more than $1.45 \mathrm{~kg}$. The $2{ }^{\circ} \mathrm{C}$ lower drying start temperature in Fig. 6 means that the new drying method is more effective. When increasing the heat of the experimental setup by $2{ }^{\circ} \mathrm{C}$, from 46 to $48^{\circ} \mathrm{C}$ using the electrical element, the measurements showed an electricity consumption of $0.039 \mathrm{kWh}$. This means that the new drying method decreases the electricity consumption of $0.039 \mathrm{kWh}$ comparing the existing drying method (method $\mathrm{c}$ in Fig. 2).
Fig. 5 Temperatures out and into the dishwasher and relative humidity out of the dishwasher (see Fig. 3). These curves are from the experiment in test series 2 with $1.03 \mathrm{~kg}$ ice, 90-min drying time, airflow of $8 \mathrm{~m}^{3} / \mathrm{h}$ and $46^{\circ} \mathrm{C}$ drying start temperature

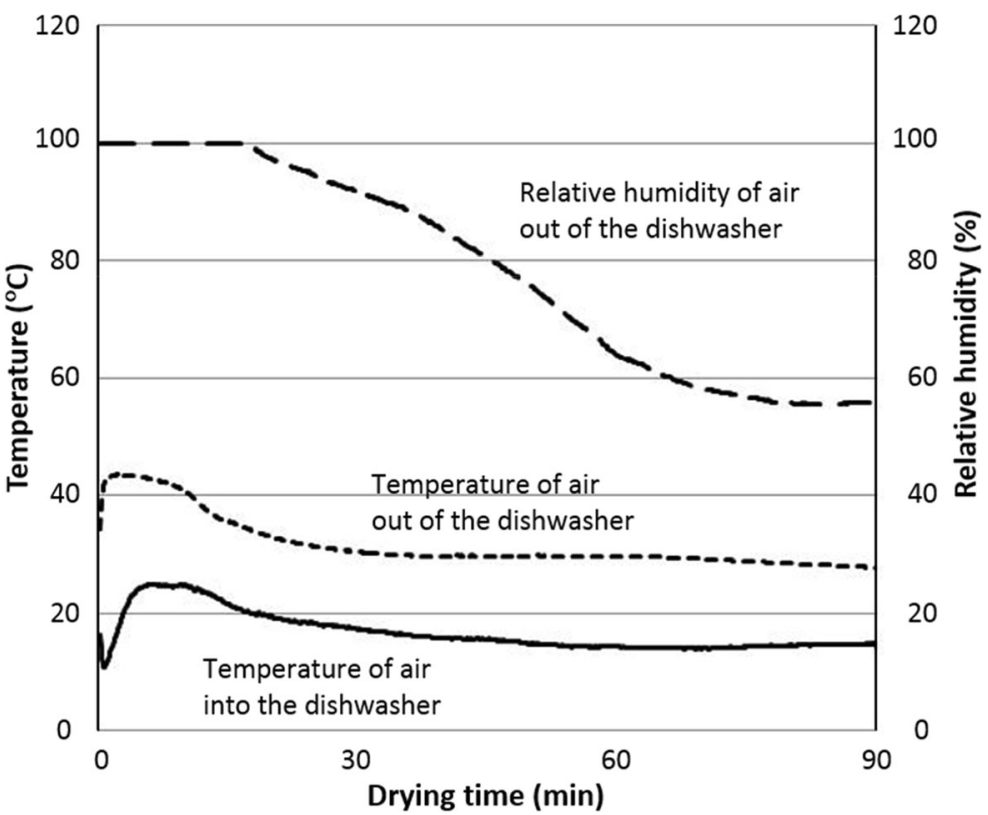




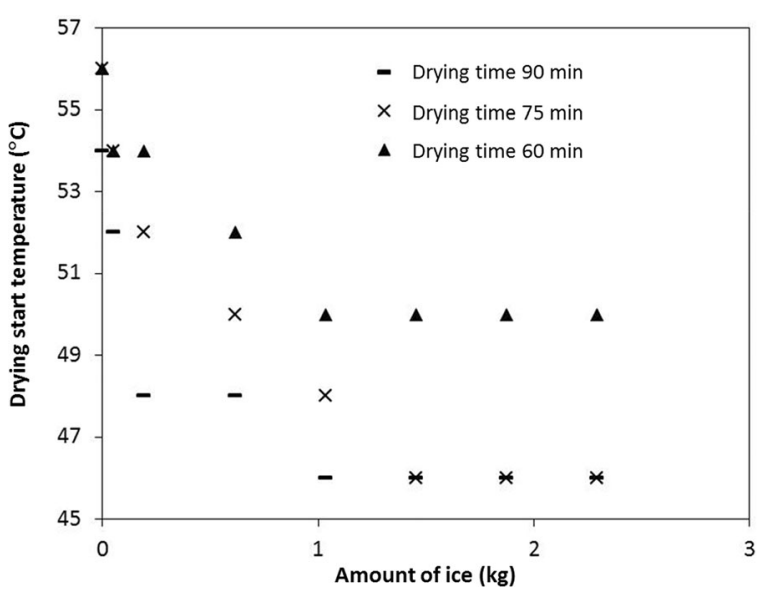

Fig. 6 Experiments in test series 2 where the drying performance was just above 1.58 according to visual inspection, with an uncertainty of $\pm 0.5^{\circ} \mathrm{C}$. In all experiments, the airflow was $8 \mathrm{~m}^{3} / \mathrm{h}$

The lack of space inside a dishwasher, together with the demand for low costs in the household industry, limits the design of the components. This is a general limitation and a major challenge for a manufacturer when developing a product such as a heat pump dishwasher. Both the water tank, air duct and the fan will need space. In my opinion, it is possible that a welloptimized design of these components will fit in a final design of a heat pump dishwasher.

The results in Fig. 6 show that a higher drying start temperature is required when the amount of ice is lower, between 1.03 and $0 \mathrm{~kg}$. Above $1.03 \mathrm{~kg}$ (for 60 and 90 min drying time) and $1.45 \mathrm{~kg}(75 \mathrm{~min})$, there was enough ice in the water tank for the whole drying step. This can be explained by referring to the curves in Fig.
7. The curves in Fig. 7 are examples to show the behaviour of the ice in the water tank.

Figure 7 shows that the temperature of the upper part of the water tank increased first, followed by the other positions, indicating that the ice was melting from the top to the bottom of the water tank. This was expected because the inlet of the warm humid air from the dishwasher cabinet was at the top of the water tank (see Fig. 3 ). The temperature of the lower part of the water tank was beginning to increase towards the end of the drying step. That indicates that almost all the ice was melted and that the amount of ice was just sufficient to last for the entire drying step. As long as there is some ice in the water tank throughout the whole drying step, the drying is effective. However, as soon as all the ice melted and the temperature of the water tank increased, the drying efficiency was reduced. A simple energy balance between the energy storage and airflow in and out of the dishwasher indicates that about $1 \mathrm{~kg}$ ice is sufficient for the drying process in this experimental setup.

The temperatures in Fig. 7 do not go to $0{ }^{\circ} \mathrm{C}$ because the temperatures were measured on the outer surface of the water tank, while the ice was inside the water tank. However, the purpose of these temperatures was to show the behaviour of the water tank.

Figure 8 shows the total amount of condensation from the cold surface on the water tank when the airflow was $8 \mathrm{~m}^{3} / \mathrm{h}$ and the drying time was $90 \mathrm{~min}$, with a different amount of ice. The results showed different amounts of condensation from the cold surface, despite the same drying performance of 1.58. The same trends, with different amounts of condensation from the cold
Fig. 7 Temperatures on the water tank surface at three positions (see Fig. 3). The curves were taken from the experiment in test series 2 with $1.03 \mathrm{~kg}$ ice, 90 -min drying time, airflow of $8 \mathrm{~m}^{3} / \mathrm{h}$ and a drying start temperature of $46^{\circ} \mathrm{C}$

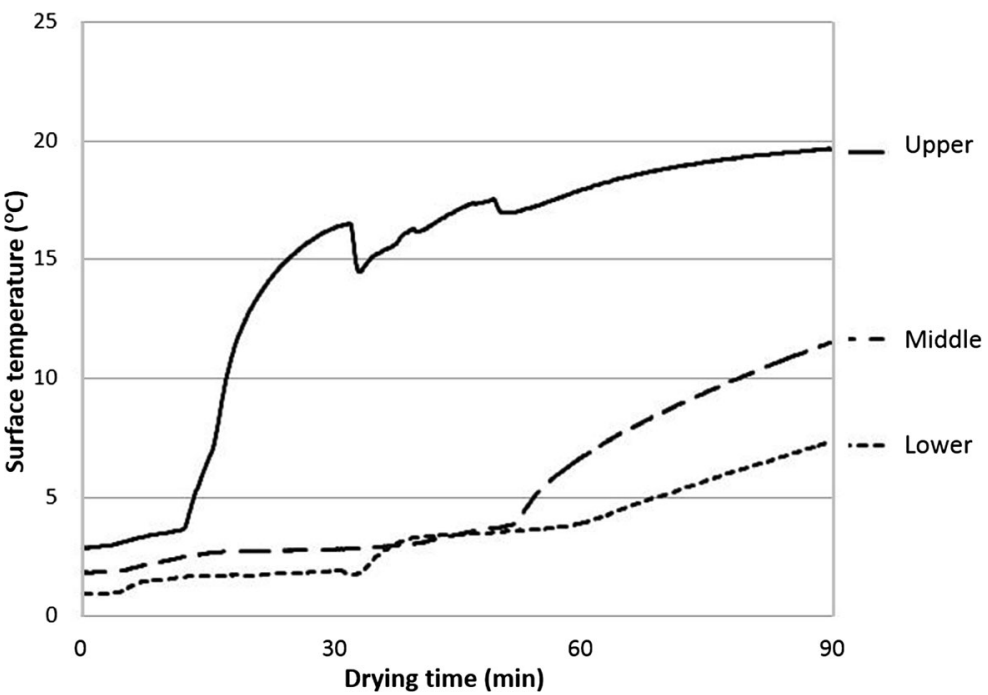


Fig. 8 Experiments in test series 2 showing the total amount of condensate from the cold surface on the water tank when the drying performance of the dishware was just above 1.58 , with an uncertainty of $\pm 1 \mathrm{~g}$. In all experiments, the airflow was $8 \mathrm{~m}^{3} / \mathrm{h}$ and the drying time was $90 \mathrm{~min}$. The drying start temperature for each experiment is shown above the bar. The amount of ice in the water tank when drying starts is shown below the bar

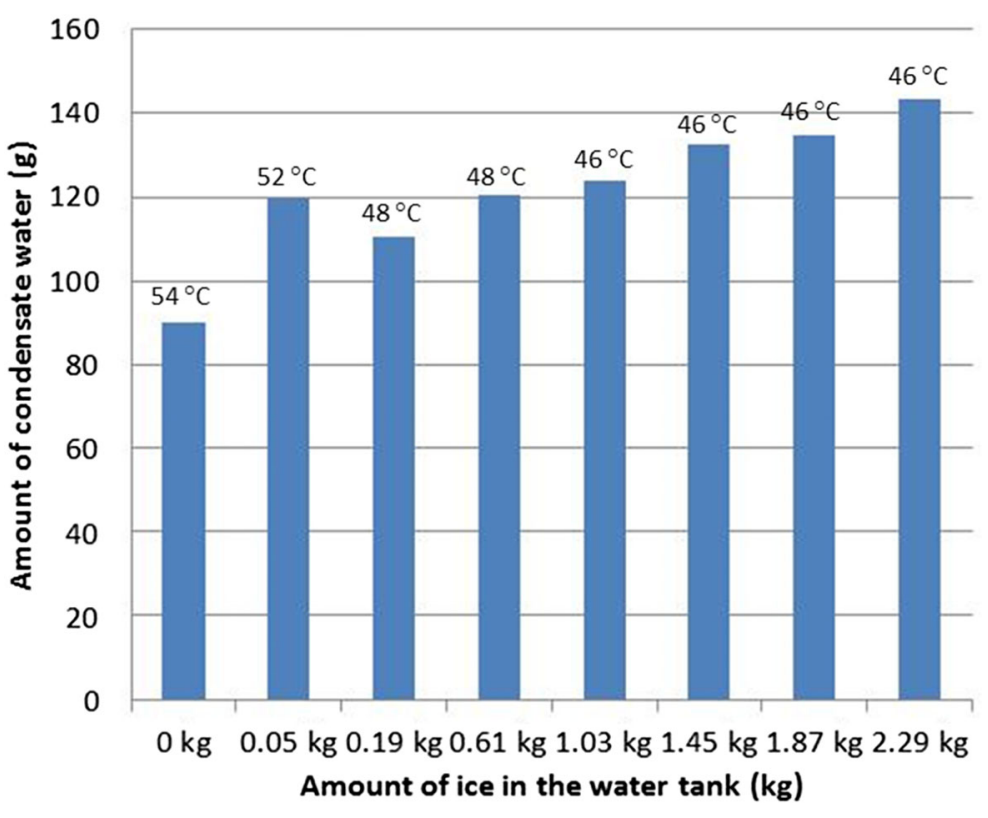

based on early assumptions and was not optimized. A combined experimental and simulation study should be performed in the future to increase the knowledge of which parameters to consider and how much they affect the drying performance.

More future studies about the effect of varying the airflow during the drying cycle would be interesting to examine. In all future experiments, the range of parameters should not be as large as in this study. The parameters should be in the range of, for example, $5 \mathrm{~min}$ for the drying time, $1^{\circ}$ for the drying start temperature and $1 \mathrm{~m}^{3} / \mathrm{h}$ for the airflow.

\section{Conclusions}

This concept study evaluates a new closed drying method for drying dishware in a heat pump dishwasher. Drying performance in an experimental setup was studied by varying the parameters airflow, drying time, amount of ice in the water tank and drying start temperature. Based on these results, which are compared to an existing open drying method, the following conclusions can be drawn:

- The new closed drying method is more energy effective than an open drying method currently on the market because it achieves the same drying performance with less accumulated energy at the start of ly. However, the design of the experimental setup was 
the drying step. This decrease the electricity consumption with $0.039 \mathrm{kWh}$.

- For each dishwasher design with this drying method, there is a minimum required amount of ice needed in the water tank to achieve the optimal drying performance. For the experimental setup in this study, the amount of ice required was about $1 \mathrm{~kg}$.

- The drying start temperature and the drying time affect the drying performance significantly.

- With this drying method, the amount of condensed water on the cold surface is not a reliable way to evaluate the dryness of dishware in the dishwasher.

Acknowledgements This study was performed within the multidisciplinary industrial graduate school Values Created in FibreBased Processes and Products (VIPP) at Karlstad University, with financial support from the Knowledge Foundation, Sweden.

Open Access This article is distributed under the terms of the Creative Commons Attribution 4.0 International License (http:// creativecommons.org/licenses/by/4.0/), which permits unrestricted use, distribution, and reproduction in any medium, provided you give appropriate credit to the original author(s) and the source, provide a link to the Creative Commons license, and indicate if changes were made.

\section{References}

ASKO dishwasher ASKOd5436 n.d. http://www.askona. com/dishwashers/built-in/d5436xls, (accessed 160915).
Bengtsson, P., \& Berghel, J. (2016). Study of using a capillary tube in a heat pump dishwasher with transient heating. International Journal of Refrigeration, 67, 1-9.

Bengtsson, P., \& Eikevik, T. (2016). Reducing the global warming impact of a household heat pump dishwasher using hydrocarbon refrigerants. Applied Thermal Engineering, 99, 12951302.

Bengtsson, P., Berghel, J., \& Renström, R. (2015). A household dishwasher heated by a heat pump system using an energy storage unit with water as the heat source. International Journal of Refrigeration, 49, 19-27.

Bosch dishwasher SHX55M06UC n.d. http://www.bosch-home. ca/SHX55M06UC.html\#tab2, (accessed 160915).

EN50242. (2008). Methods for measuring the performance.

Hauer, A., \& Fischer, F. (2011). Open adsorption system for an energy efficient dishwasher. Chemie-Ingenieur-Technik, 83, 61-66.

Jeong, G., \& Kim, Y. (2015). The effects of energy efficiency and environmental labels on appliance choice in South Korea. Energy Efficiency, 8, 559-576.

Lee, D. H., \& Jeong, S. W. (2014). Drying performance of a dishwasher with internal air circulation. Korea J Chem Eng, $31,1518-1521$.

Mujumdar, A.S.. (1995) Handbook of industrial drying, Marcel Dekker Inc.

Sai, P.S.T.. Linga, A.. (2010). Studies on drying kinetics of solids in a rotary dryer, 3rd International Conference on Thermal Issues in Emerging Technologies, Theory and Applications. ThETA3. Cairo, Egypt 389.

Samsung dishwasher DW60H9970SA n.d. http://www.samsung. $\mathrm{com} / \mathrm{nz} / \mathrm{consumer/home-appliances/dishwashers/}$ dishwashers/DW60H9970FS/SA, (accessed 160915).

Santori, G., Frazzica, A., Freni, A., Galieni, M., Bonaccorsi, L., Polonara, F., \& Restuccia, G. (2013). Optimization and testing on an adsorption dishwasher. Energy, 50, 170-176. 